\title{
A disciplinarização da produção textual escrita na educação básica brasileira: reflexos no trabalho docente
}

\author{
The disciplinarization of textual production written \\ in brazilian basic education: reflections in teaching work \\ Fabiana Veloso de Melo Dametto \\ Universidade Federal de Santa Maria (UFSM), Santa Maria, RS, Brasil
}

Jeferson Luís Carvalho

Universidade de Santa Cruz do Sul (UNISC), Santa Cruz do Sul, RS, Brasil

Marcia Cristina Corrêa

Universidade Federal de Santa Maria (UFSM), Santa Maria, RS, Brasil

Resumo: Muitas foram as intervenções governamentais com o objetivo de produzir/ provocar transformações na Educação Básica brasileira. Este trabalho, no entanto, tem como objetivo refletir acerca de uma prática instaurada por iniciativa de escolas e a qual vem se consolidando de maneira silenciosa e à parte das prescrições oficiais. Trata-se da implantação de uma disciplina denominada Redação. Esse movimento é autônomo, mas não orgânico. A criação de uma disciplina implica pensar uma multiplicidade de aspectos envolvidos nesse processo. Para tanto, este trabalho tem como ponto de partida trocas de experiências vivenciadas por profissionais da Educação Básica. Por essa razão, a fala produzida aqui é de professores-pesquisadores dirigindo-se aos formadores de professores. Além disso, busca-se estabelecer, à luz do Interacionismo Sociodiscursivo e da Ergonomia da atividade docente, uma articulação entre discurso científico e práticas docentes.

Palavras-chave: Ensino. Produção Textual. Redação. Trabalho Docente.

Abstract: Many were governmental interventions aimed at producing/provoking transformations in Brazilian Basic Education. This work, however, aims to reflect on a practice established by the initiative of schools and which has been consolidating in a silent way in part of the official prescriptions. This is about the implementation of a discipline called Redação (Writing). This movement is autonomous, but not organic. The creation of a discipline implies thinking about a multiplicity of aspects involved in this 
Fabiana Veloso
de MeloDametto

Jeferson Luís

Carvalho

Marcia Cristina

Corrêa

process. Thereunto, this work has as starting point exchanges of experiences experienced by professionals of Basic Education. For this reason, the talk produced here is from teacher-researchers to teacher trainers. Furthermore, it seeks to establish, in the light of Sociodiscursive Interactionism and Ergonomics of teaching activity, a link between scientific discourse and teaching practices.

Key words: Education. Text Production. Wording. Teaching Work.

\section{Introdução: a história que não é contada}

Maria Docência Brasil, em 2012, graduada em Letras-Português e à procura da primeira oportunidade de emprego formal, foi convidada pela equipe diretiva de uma escola privada de Educação Básica para ser professora de Redação. A direção geral da instituição havia decidido que "os alunos precisavam escrever mais" e, para tanto, era preciso incluir no currículo uma disciplina obrigatória focada somente no ensino da escrita. Afinal, na perspectiva do proprietário da escola, era isso que escolas com bom desempenho no Exame Nacional do Ensino Médio (Enem) e vestibulares vinham fazendo nos últimos anos.

Um período por semana com cada turma. Inacreditável! Ela sempre sonhara em ser professora de Redação, como aquelas de cursinho pré-vestibular: renomadas, que dão entrevistas nas rádios e TVs, que dão dicas de Redação a jornais. A resposta não poderia ser outra: sim!

Professora de Redação de todas as turmas do Ensino Fundamental II (do $6^{\circ}$ ao $9^{\circ}$ ano) e do Ensino Médio (do $1^{\circ}$ ao $3^{\circ}$ ano). Dez turmas no total. Ela gostou da proposta, pois acreditava que ensinar especificamente escrita, no formato de uma disciplina independente de Língua Portuguesa, seria muito produtivo.

Motivada, a professora iniciante questionou a direção da escola sobre qual seria o objetivo da nova disciplina: preparar os alunos para o Enem; preparar para os vestibulares locais; preparar para as práticas de escrita do ensino superior; preparar para as práticas de escrita sociais. Afinal, ela precisava saber qual seriam o foco e o perfil da Redação como disciplina escolar. A resposta recebida foi curta e simples: "o objetivo é fazer as crianças escreverem mais, coloque essa 'gurizada' para escrever!".

Aceito o convite, a escola solicitou a ela a apresentação, às pressas, de um plano anual de ensino de Redação para cada uma das turmas. A surpresa: a escola não contava com material didático específico para a disciplina. Logo, Maria Docência viu-se na seguinte situação: professora de dez 
turmas, responsável por uma disciplina sem plano de ensino, sem material didático e sem metodologia de ensino e de avaliação definidas. Cabia à professora ainda inexperiente definir e construir esses instrumentos didáticos.

Nas primeiras aulas do ano letivo, ainda sem o planejamento anual definido, a estratégia foi solicitar a todas as turmas a mesma atividade: produção textual de uma narrativa. Com isso, ela acreditou que ganharia tempo de organizar suas aulas. Foi então que os problemas começaram a ganhar complexidade.

O primeiro deles foi conseguir dar conta de corrigir com cuidado cada uma das produções de todos os alunos das dez turmas assumidas. Eram muitos textos! Trabalho extraclasse para semanas. Os alunos passaram a ficar ansiosos pelo retorno das avaliações. Contudo, na semana seguinte, foi preciso envolvê-los em outra tarefa de escrita, e assim na

Adisciplinarização da produçãotextual escritana educação básica brasileira próxima semana, na outra e na outra. Resultado: pilhas e mais pilhas de textos para corrigir, e o bimestre chegando ao fim.

As demais dificuldades estavam por vir. Os pais queriam saber o desempenho dos filhos em Redação; os alunos queriam saber suas notas na disciplina; e ambos (pais e alunos) criaram a expectativa de que, a cada aula, seria produzida uma nova redação. Além disso, aqueles com maiores dificuldades em escrita demandavam atenção especial durante as aulas. A direção da escola passou a cobrar que os alunos do Ensino Médio fossem preparados para a prova de redação do Enem. O caos, inevitavelmente, se instaurou.

Maria Docência não conseguia conversar com os professores de Língua Portuguesa de algumas turmas. Ela não conhecia o planejamento das demais disciplinas que poderiam dar suporte à Redação. Ela não sabia ao certo a diferença entre ser professora de Língua Portuguesa e de Redação. Afinal, o que cabia a cada uma dessas disciplinas em sala de aula?

Maria Docência não fazia ideia de como encontrar as respostas que procurava, ela havia sido preparada para ser uma professora de Língua Portuguesa que trabalharia em sala as quatro habilidades linguísticas de forma conjunta e integrada: leitura/compreensão; escrita; oralidade e análise linguística. É essa a orientação presente nos Parâmetros Curriculares Nacionais de Língua Portuguesa, desde 1998 (assim ela acreditava!).

Gradativamente a professora afundou em um sentimento de fracasso. Havia constatado que era inviável ser professora de Redação de tantas turmas ao mesmo tempo; que não valia a pena financeiramente essa atividade, visto que o volume de trabalho extraclasse era infinita- 
Fabiana Veloso de Melo Dametto

Jeferson Luís

Carvalho

Marcia Cristina

Corrêa

mente maior que o de qualquer outra área; que era humanamente impossível corrigir tantos textos em um espaço de tempo tão curto; que ela não sabia ao certo o que deveria ser ensinado nessas aulas; que ela não sabia como mensurar o desempenho dos alunos em diferentes níveis de aprendizagem; que ela não tinha noção se deveria trabalhar com gêneros textuais diversos, ou com tipologias textuais, por exemplo; se ela deveria abordar nas aulas aspectos de ordem gramatical ou apenas os estruturais referentes aos formatos de textos explorados. Enfim, ela chegou à conclusão que não havia sido preparada durante o curso de Letras para ser professora de Redação e que estava sozinha, pois não sabia a quem recorrer. Foi preciso, então, reavaliar sua decisão e refazer alguns caminhos.

Este breve relato, aqui apresentado, tem por base as experiências profissionais vivenciadas por quatro professores formados e pós-graduados em Letras. Dois deles são autores deste artigo. Todos atuaram ao longo dos últimos cinco anos como professores de Língua Portuguesa e de Redação, na mesma escola privada. Entretanto, possivelmente esta seja também a história de muitos outros profissionais formados em Letras, no Brasil, desde a famigerada "Crise na Linguagem"1, que fora identificada e muito discutida entre o final dos anos de 1970 e o início do anos 80 - após o processo de democratização da Educação Básica brasileira.

Sabemos que, na atualidade, escolas privadas e públicas (estaduais e federais) vêm adotando essa prática. Passaram a ofertar na grade curricular da Educação Básica uma disciplina obrigatória denominada Redação. Dependendo da instituição, o nome da disciplina varia. Há escolas em que a produção de texto escrito é praticada nas aulas de Produção de Texto ou em Leitura e Produção de Texto. Outras dispõem de um Laboratório de Redação, com aulas semanais e atividades avaliativas. Em outras, há Oficinas de Redação com a mesma função e formato.

Com isso, passou-se a ter, nessas instituições, uma carga-horária específica destinada ao ensino e à aprendizagem da produção textual escrita. $O$ resultado desse processo tem sido uma aparente fragmentação do ensino da competência linguística, uma vez que há no currículo disciplinas distintas responsáveis por desenvolvê-la: Literatura, Língua Portuguesa e Redação. O termo "aparente" está sendo aqui empregado

1 Ver, por exemplo, a seguinte obra: ROCCO, Maria Thereza. Crise na linguagem: a redação no vestibular. São Paulo: Mestre Jou, 1981. 
em virtude da pesquisa estar em andamento. É possível que, na prática, em algumas escolas, essas disciplinas estejam interligadas por um fio condutor (uma política de ensino bem alinhavada).

A escola privada na qual atuaram como professores dois dos autores deste artigo (de 2012 a 2016), por exemplo, implantou, em 2012, uma disciplina denominada Redação que consiste em um período semanal em cada turma do Ensino Fundamental II (EFII) e de todo Ensino Médio (EM). Para tanto, foi reduzida a carga-horária de Língua Portuguesa: de cinco períodos, passou-se a ter apenas quatro por semana em cada turma, e um foi destinado à Redação. Cumpre destacar que essa decisão não passou pela apreciação dos professores de Língua Portuguesa e de Literatura. Esta foi uma atitude adotada pela direção geral da instituição, com o objetivo de "colocar os alunos a escrever mais".

A disciplinari-
zação da produ-
ção textual
escrita na
educação básica
brasileira

o desafio desses profissionais e o de outros da área passou a ser ministrar uma disciplina que, para eles, era "nova", sem plano de ensino e sem material didático. $\mathrm{E}$ cabe destacar que o termo está entre aspas porque estudos mais aprofundados estão mostrando que essa prática já existe desde a década de 1970 em algumas instituições, em especial nos cursos preparatórios e em escolas de referência. Além disso, a redação está presente como objeto de ensino na sala de aula de Educação Básica há muito tempo. o que vamos discutir aqui é a disciplina de Redação na atualidade, bem como a disseminação indiscriminada dessa prática não só na rede privada, como também nas diferentes redes públicas (estadual e federal), as quais são de natureza, estrutura e público-alvo muito distintos na maioria dos casos.

Esse contexto, aqui brevemente apresentado, gerou nos professores envolvidos uma infinidade de dúvidas, preocupações e angústias. Buscaremos, então, na sequência deste artigo, explanar e problematizar os aspectos mais pontuais que estão no cerne dessa prática.

\section{A disciplinarização da produção textual escrita: ponto de partida}

Antes de abordarmos possíveis implicações da implantação da disciplina de Redação na Educação Básica brasileira, é necessário esclarecer a concepção de disciplina assumida neste estudo. Para tanto, partiremos da História da Educação, mais precisamente da História das Disciplinas Escolares, baseada nos aspectos teórico-metodológicos de uma prática historiográfica, conforme defendida por um de seus principais representantes, o linguista e historiador francês André Chervel. 
Segundo esse pesquisador (1990, p. 180), o termo disciplina, empregado para designar os conteúdos de ensino escolares, surgiu no início do século XX. O autor esclarece que, comumente, acredita-se que

Fabiana Veloso de Melo Dametto

Jeferson Luís Carvalho

Marcia Cristina Corrêa esses conteúdos "são impostos como tais à escola pela sociedade que a rodeia e pela cultura na qual ela se banha" e que, além disso, cabe à escola apenas fazer a transposição dos conhecimentos produzidos fora dela, na academia (conhecimento científico).

Chervel (1990) defende, no entanto, que a escola não é simplesmente o "lugar da inércia, do conservadorismo", isto é, "a escola não se define por sua função de transmissão dos saberes" (p. 181). Diferentemente dessa visão que Chervel qualifica como "redutora", ele defende que a escola tem um poder criativo e uma autonomia que permitem a esse sistema formar uma cultura própria, que acaba por exercer influência na cultura da sociedade global, ao mesmo tempo em que forma os indivíduos.

Nessa perspectiva, o objeto de estudo são os conteúdos escolares, as práticas concretas de ensino, ou seja, passa-se a olhar a escola de dentro dela mesma. A partir desses pressupostos, Chervel (1990) defende que, ao se buscar entender a constituição das disciplinas, três problemas de diferentes ordens são colocados diante do pesquisador, isto é, problemas referentes: à gênese, à função e ao funcionamento das disciplinas.

Apesar de Chervel (1990) atribuir à escola um poder que ele chama de criativo, uma autonomia, ao longo de seu texto base, ele relaciona os três problemas apontados a aspectos que, na maioria das vezes, estão fora da escola, tais como as finalidades do ensino. Por essa razão, entendemos que exista uma interdependência entre determinantes internos e externos no que se refere à constituição de uma disciplina escolar.

Partindo desses pressupostos teóricos e à luz do Interacionismo Sociodiscursivo e da Ergonomia da atividade docente, esta pesquisa, ainda bastante inicial, tem buscado primeiramente compreender as condições sócio-históricas específicas que estão na gênese dessa disciplina e possibilitaram o processo de disciplinarização da produção textual escrita em inúmeras escolas de Educação Básica, em especial nos últimos anos, no Brasil. Até o presente momento, de acordo com Dametto (no prelo), sabe-se que, em diferentes estados e cidades brasileiras, há escolas privadas e públicas (estaduais e federais) que ofertam, na grade curricular do EM, a disciplina de Redação. 
Este é o caso dos seguintes Estados/cidades já consultados ${ }^{2}$ pela pesquisadora: SP/São Paulo; CE/Fortaleza; PI/Teresina; MG/Belo Horizonte; DF/Brasília; RJ/Petrópolis; PE/ Recife; RS/Santa Maria; PR/Curitiba; BA/Feira de Santana. Algumas dessas escolas aumentaram a carga horária da área de Linguagens e, com isso, conseguiram encaixar a Redação. Outras, porém, diminuíram a carga horária de Língua Portuguesa, cedendo, neste caso, um período à Redação - a maioria das escolas consultadas denominou desta forma a disciplina que aborda a prática de ensino de produção textual escrita.

$\mathrm{Na}$ busca por compreender as condições sócio-históricas em torno das quais surgiu essa nova disciplina, percebemos que um olhar panorâmico do sistema educacional brasileiro nos permite afirmar que muitas foram as transformações ocorridas na Educação Básica do país Adisciplinarização da produção textual escritana educação básica brasileira e que, certamente, ainda ocorrerão. Assistimos, nas últimas décadas, inúmeras tentativas de nossos governantes (quase sempre pressionados pelo apelo da sociedade), em especial nas esferas nacional e estadual, de minimizar problemas de naturezas distintas na educação: dificuldade de acesso ao sistema público de ensino; sucateamento das escolas; falta de professores; cursos de licenciatura de baixa qualidade; desvalorização do trabalho docente; falta de interesse dos alunos pela educação formal; baixo desempenho dos alunos nas avaliações de larga escala (PISA ${ }^{3}$, Prova Brasil ${ }^{4}$, Saeb e Enem).

Neste sentido, presenciamos ações que ampliaram o número de escolas públicas, que formaram professores a "toque de caixa" para atender à demanda de ampliação da rede pública; que modificaram a denominação e os ciclos da educação básica; que extinguiram disciplinas; que exigiram dos profissionais da educação formação em curso superior; que implantaram documentos oficiais com a função de modi-

2 O levantamento está sendo realizado com base no Ranking do Enem 2015. A escola melhor colocada de cada Estado está sendo contatada via telefone para que se possa obter a informação referente à existência ou não da disciplina de Redação na instituição. Até o momento, onze escolas foram consultadas. Dessas, dez oferecem a disciplina de Redação.

3 O Programme for International Student Assessment (Pisa) - Programa Internacional de Avaliação de Estudantes - é uma iniciativa de avaliação comparada, aplicada de forma amostral a estudantes matriculados a partir do $8^{\circ}$ ano do Ensino Fundamental na faixa etária dos 15 anos, idade em que se pressupõe o término da escolaridade básica obrigatória na maioria dos países. No Brasil, a coordenação do Pisa é responsabilidade do Inep. Fonte: http://portal.inep.gov.br/web/guest/pisa. Acesso em: 10 de Fevereiro de 2017.

4 A Prova Brasil e o Sistema Nacional de Avaliação da Educação Básica são avaliações para diagnóstico, em larga escala, desenvolvidas pelo INEP/MEC.. Fonte: http://portal.mec.gov.br/prova-brasil. Acesso em: 10 de fevereiro de 2017. 
Fabiana Veloso de Melo Dametto

Jeferson Luís

Carvalho

Marcia Cristina

Corrêa

178

ficar e prescrever práticas docentes; que aumentaram os anos de permanência do aluno no Ensino Fundamental; que instauraram exames de escala nacional para aferir a aprendizagem dos alunos e garantir o ingresso no ensino superior e, neste momento (início de 2017), estamos acompanhando a aprovação da Reforma do Ensino Médio ${ }^{5}$ e a criação de uma Base Nacional Curricular Comum ${ }^{6}$.

Portanto, muitas foram as intervenções governamentais com o objetivo de produzir/provocar transformações na Educação Básica brasileira. Muitas delas foram/são fundamentadas e até motivadas por pesquisas desenvolvidas no âmbito acadêmico brasileiro e internacional. No entanto, outras intervenções baseiam-se mais na opinião de profissionais que atuam fora da academia e da escola, servindo, dessa forma, muito mais a interesses de ordem político-econômica do que aos anseios da sociedade em geral.

Já este trabalho especificamente tem como objetivo refletir acerca de uma mudança instaurada por iniciativa de escolas de Educação Básica brasileiras. Trata-se, como já foi explicado, de uma prática que vem se consolidando de maneira silenciosa e à parte das prescrições presentes nos documentos oficiais do país e das pesquisas mais recentes sobre ensino de língua materna: a implantação, ao longo da Educação Básica, de uma disciplina denominada, na maioria dos casos, Redação, a qual tem como função desenvolver o ensino da produção textual escrita.

Percebemos que esse movimento é autônomo, mas não orgânico, isto é, ele não é fruto das reflexões acadêmicas e das práticas docentes, muito menos da consciência de que é necessário repensar os modos de se ensinar a produção escrita na Educação Básica e até na Educação Superior. Na realidade, ele resulta de forças que atuam muito além da escola, mas que se refletem direta/indiretamente em suas práticas. Um exemplo dessa influência externa que chega à escola é a implantação do Enem e o protagonismo atribuído à redação (produção de texto escrito) ao lado das quatro áreas do conhecimento avaliadas por esse processo (Ciências Humanas, Ciências da Natureza, Linguagens e Matemática).

5 Trata-se de uma mudança na estrutura do sistema atual do ensino médio. A nova estrutura terá uma parte que será comum e obrigatória a todas as escolas (BNCC) e outra parte flexível. Fonte: http:// portal.mec.gov.br/component/content/article?id=40361\#nem_04. Acesso em: 10 de Fevereiro de 2017.

6 É um conjunto de orientações que deverá nortear os currículos das escolas, redes públicas e privadas de ensino de todo o Brasil. A Base trará os conhecimentos essenciais, as competências e as aprendizagens pretendidas para as crianças e jovens em cada etapa da Educação Básica em todo país. Fonte: http:// basenacionalcomum.mec.gov.br/\#/site/faq\#secao1-questao1. Acesso em: 10 de Fevereiro de 2017. 
Ao longo das últimas décadas, muito se tem discutido sobre o baixo desempenho dos alunos em leitura e escrita. Essas deficiências ficaram ainda mais evidentes com o procedimento de divulgação pública do desempenho das escolas no Enem, o famoso Ranking do Enem, recentemente extinto. Conforme informações divulgadas no site do INEP - Instituto Nacional de Estudos e Pesquisas Educacionais Anísio Teixeira, o Enem "foi criado em 1998 com o objetivo de avaliar o desempenho do estudante ao final de sua jornada pela educação básica, buscando contribuir para a melhoria na qualidade da escolarização". Contudo, em 2004, o exame passou a ser utilizado também como mecanismo de seleção para o ingresso no Ensino Superior. Somado a isso, com a utilização do Enem para a certificação de conclusão do EM, ou mesmo para o acesso aos programas federais de financiamen-

Adisciplinarização da produção textual escritana educação básica brasileira

\section{As prescrições oficiais para o ensino de língua materna no Brasil}

Neste debate, não podemos deixar de citar - mesmo que de forma breve - as orientações sobre o ensino e a aprendizagem da Língua Portuguesa que constam nos PCN's. Conforme explica Gomes (2014, p. 40), este documento, "vigente desde sua publicação em 1998, orienta para o uso do texto como unidade básica de ensino, por concebê-lo como produto de práticas sociais situadas". Além disso, há uma orientação clara para o ensino de Língua Portuguesa de modo integrado, ou seja, por áreas do conhecimento.

Inserida nesse movimento, surge a atual preocupação do Governo Federal em propor uma Base Nacional Curricular Comum para as escolas de Educação Básica. Esse documento ainda está em desenvolvimento e tem por base os pressupostos teóricos e práticos já defendidos pelos PCN's. No que diz respeito especificamente à disciplina de Língua Portuguesa, a proposta preliminar da Base (BNCC, 2016) pontua que:

7 VICENTINI, Mônica Panigassi. A redação no ENEM e a redação no $3^{0}$ ano do ensino médio: efeitos retroativos nas práticas de ensino da escrita. Dissertação (mestrado). UNICAMP. Campinas, SP: [s.n.], 2015. Orientador: Matilde Virginia Ricardi Scaramucci. 


\section{Fabiana Veloso \\ de Melo Dametto}

Jeferson Luís

Carvalho

Marcia Cristina

Corrêa

[...] na esteira do que foi proposto nos Parâmetros Curriculares Nacionais, o texto ganha centralidade nos objetivos de aprendizagem e desenvolvimento, tomado como gênero textual/discursivo em esferas sociais de uso. [...] No Ensino Médio, o componente curricular Língua Portuguesa - a exemplo dos demais componentes - precisa lidar com o agravamento da fragmentação do conhecimento. Essa fragmentação - não obstante o esforço de constituição de áreas do conhecimento, já propostas nas Diretrizes Curriculares para o Ensino Médio de 1998 (BRASIL, 1998) - é desafio a ser enfrentado ainda hoje e pode ser observada mesmo no interior do componente, em separações que isolam, por exemplo, contemplando temas que impactam a cidadania e o exercício de direitos (BNCC - Proposta Preliminar, abril 2016, p. 523-524, grifos nossos).

Na BNCC (2016, p. 523-524), portanto, há uma orientação clara referente à necessidade do componente curricular Língua Portuguesa "lidar com o agravamento da fragmentação do conhecimento". Nesta proposta, as disciplinas passam a ser agrupadas por áreas do conhecimento e são denominadas de componentes curriculares. Cada componente é formado por eixos de ensino. No caso do componente Língua Portuguesa, ele está constituído por quatro eixos: leitura; escrita; oralidade e conhecimentos sobre a língua e a norma.

Em função do que até aqui foi apresentado em linhas muito gerais, podemos afirmar que, do ponto de vista das políticas públicas de ensino, as escolas que ofertam em sua proposta curricular uma disciplina de Redação estão na contramão das diretrizes nacionais de Ensino Básico e da maioria das teorias sobre ensino de produção textual. No entanto, ainda assim, essa prática parece estar se fortalecendo e enraizando. Neste caso, prescrições, teorias e práticas de ensino parecem estar caminhando em sentidos opostos. Logo, é preciso discutir no meio acadêmico o que está, de fato, por trás desse movimento e quais serão suas implicações para a Educação Básica brasileira e para a formação de professores.

\section{Possíveis implicações decorrentes da disciplinarização da escrita}

A disciplinarização da produção textual escrita na Educação Básica - a partir da noção de disciplina que a entende como um sistema que possui uma estrutura própria, uma economia interna e uma organização 
específica - envolve uma multiplicidade de aspectos sobre os quais precisamos (agentes públicos, pesquisadores, professores e sociedade) refletir.

Nesse processo estão envolvidos não apenas aspectos de natureza didática e acadêmica/científica, ou mesmo de natureza política (políticas públicas de ensino), que poderiam estar na sua gênese; mas também, e fundamentalmente, aspectos de natureza operacional (funcionamento) e até mercadológica (função), os quais se refletem diretamente nas práticas de sala de aula e, consequentemente, no trabalho docente.

Este pequeno artigo centra suas reflexões nos aspectos de natureza didático-operacional referentes à implantação da disciplina de Redação. Para tanto, muitos questionamentos serão levantados, entretanto, não serão necessariamente respondidos neste momento, visto que a pesquisa está em

\author{
Adisciplinari- \\ zação da produ- \\ ção textual \\ escritana \\ educação básica \\ brasileira
} fase inicial e demanda que muitos outros professores e escolas sejam consultados para que se possa ter um mapeamento mais aprofundado da situação.

Esta proposta apresenta-se, portanto, como um enorme desafio. Isso porque se propõe a investigar e a analisar uma história em movimento, e essa problemática se justifica na medida em que se admite que "a presença de cada uma das disciplinas escolares no currículo, sua obrigatoriedade ou sua condição de conteúdo opcional e, ainda, seu reconhecimento legitimado por intermédio da escola, não se restringe a problemas epistemológicos ou didáticos", mas se articula a questões maiores, tais como "o papel político que cada um desses saberes desempenha ou tende a desempenhar, dependendo da conjuntura educacional", uma vez que essa disciplina assume um papel em uma configuração social maior e que a precede (BITTENCOURT, 2003, p. 10).

\subsection{Aspectos de natureza didático-operacional}

I) A denominação da disciplina: é Redação ou Produção de Texto? Quais as implicações decorrentes dessa escolha? o que os pais e os alunos esperam de uma disciplina com essas denominações? Quais os objetivos da escola em termos de política de ensino de língua materna e de escrita quando opta por ofertar uma disciplina dessas? Há alguma preocupação e/ou intenção de criação de uma política de ensino de língua materna por parte da escola? A serviço de quem e do que essa disciplina passa a atuar?

Paulo Coimbra Guedes, renomado professor da UFRGS, com grande experiência em ensino de escrita para diferentes níveis de formação, discute essa questão da denominação da atividade destinada à prática de escrita 
nas instituições de ensino. Na obra Da redação à produção textual: o ensino da escrita (2009), o autor apresenta uma seção denominada "Composição, Redação, Produção de textos: o que diz o nome a respeito do que se discute".

Fabiana Veloso de Melo Dametto

Jeferson Luís Carvalho

Marcia Cristina Corrêa Nesta, o autor afirma que essas três expressões são sinônimas, visto que designam o mesmo fenômeno. No entanto, explica ele que, na prática, esses termos "distinguem-se [...] por se vincularem a teorias que expressam diferentes formas de considerar não só a ação de escrever textos, ação de ensinar a escrever textos e a ação de exercitar a linguagem, mas também nossa própria organização social” (GUEDES, 2009, p. 88-89).

Além disso, o autor esclarece que "a palavra Composição, usada para designar textos escritos na escola, é a mais antiga” (p. 88). Já o termo Redação passou a ser empregado "a partir do desenvolvimentismo dos anos 1950, perpassa todo o período do chamado milagre econômico e começa a findar com a crise econômica da segunda metade dos anos 1970" (p. 89). Por fim, a Produção de texto, pontua Guedes, é o termo “mais recente, como o que está na moda" (p. 90).

$\mathrm{O}$ autor explica que a Composição "vincula-se à mesma teoria que dá embasamento à gramática tradicional e vê a linguagem como instrumento de organização do pensamento" (p. 88). A Redação "expressa a eficiência tecnocrática dos engenheiros, economistas, administradores, politicólogos civis e militares" (p. 89) e, por isso, entende a linguagem como "meio de comunicação, um código, pelo qual o emissor cifra sua mensagem, que será decifrada pelo receptor" (p. 89).Já a Produção de texto, de acordo com Guedes (2009), "expressa a ação de escrever textos como um trabalho entre outros [...]. Não se trata de compor, isto é, de juntar com brilho, nem de redigir, isto é, de organizar, mas de produzir, transformar, mudar, mediante a ação humana, o estado da natureza com vistas ao interesse humano" (p. 89-90).

Esta última concepção de escrita na escola "revela a generalizada desconfiança das soluções milagrosas geradas em inodoros gabinetes tecnocráticos e aponta para a produção concreta, para o trabalho direto com a matéria-prima" (p. 90), defende o autor. Contudo, Guedes (2009) faz um alerta importante: "mudar o nome da coisa não muda a coisa" (p. 91). Em outras palavras, quando a equipe diretiva de uma escola opta por um desses termos, nem sempre tem a noção das implicações teóricas e práticas decorrentes das filiações epistemológicas dos termos empregados. Acreditamos, ademais, que muitas instituições e professores desconheçam, inclusive, toda a complexidade envolvida no processo de ensino e de aprendizagem da produção textual. 
Uma disciplina denominada Redação - como mostrou a prática dos professores-pesquisadores envolvidos neste estudo - pode levar escola, alunos e pais a acreditarem que será explorado em aula apenas o gênero textual/discursivo Redação Padrão Vestibular/Enem, isto é, o texto dissertativo-argumentativo ou, ainda, que a cada aula os alunos produzirão uma redação. Neste caso, o texto pode ser compreendido duplamente como produto, e não como processo: produto de uma prática artificializada/descontextualizada, fechada em si mesma e com base em modelos a serem seguidos; e/ou como produto mensurável, explorável e vendável, focado nos vestibulares e Enem.

Sabe-se, por exemplo, que muitas escolas, em especial as privadas, usam os resultados obtidos no Enem como melhor lhes convém, ou seja, como uma estratégia de marketing para atrair novos alunos. AlAdisciplinarização da produção textual escritana educação básica brasileira gumas divulgam na mídia as notas individuais de alunos com melhor desempenho no exame. Outras trazem a público a média geral da escola; há outras que destacam a sua colocação no Ranking do ENEM por diferentes critérios: nacional, estadual, regional ou municipal. Quanto à nota de Redação, esta costuma ser divulgada de diferentes formas também: nota de alunos que obtiveram desempenho exemplar, ou mesmo a média da escola em Redação.

A publicidade desses resultados quantitativos tem motivado, inclusive, uma prática bastante discutível: a seleção de alunos pelas escolas. A mídia tem noticiado que diversas instituições de ensino bem classificadas no Ranking, por exemplo, dispõem de diferentes CNPJs (Cadastros Nacional de Pessoal Jurídica). Em um deles matriculam-se somente os alunos com melhor rendimento escolar, com isso, a escola consegue obter boas médias gerais no exame. Há escolas em que, inclusive, o terceiro ano do Ensino Médio funciona em outra unidade física, com estrutura e organização diferenciadas. E há, ainda, as que oferecem o chamado ensino integrado, o qual consiste em uma mistura exaustiva de ensino médio regular mais cursinho pré-vestibular no terceiro ano.

Portanto, quando se fala em resultados do Enem, é preciso ter cuidado com as apreciações feitas. Com base nas experiências vivenciadas nestes últimos cinco anos, acreditamos que, na maioria dos casos, os dirigentes de escolas desconheçam essas peculiaridades quando passam a usar como exemplo a ser seguido essas instituições com alto desempenho no Exame Nacional. 
Fabiana Veloso de Melo Dametto

Jeferson Luís

Carvalho

Marcia Cristina

Corrêa

Além disso, se a disciplina de Redação estiver a serviço de apenas desenvolver habilidades referentes à produção de textos no padrão vestibular/Enem, é possível que os alunos passem anos consecutivos produzindo apenas essa tipologia/gênero. Isso pode lhes causar a impressão de que escrever se resume a fazer redações com base em uma receita: introdução + desenvolvimento + conclusão + usar citações diretas de autores renomados + não empregar a primeira pessoa do singular etc. E isso não é verdade. Ser proficiente em escrita ${ }^{8}$ é o resultado de um processo longo e complexo de aprendizagem.

II) Os profissionais envolvidos: um aspecto importante da implantação da disciplina de Redação na educação básica refere-se ao profissional que atua nessa área. O professor que ministra Língua Portuguesa nem sempre é o que ministra Redação em uma mesma turma. Isso dificulta a realização de um trabalho sistematizado, progressivo e sincronizado com Língua Portuguesa e com Literatura.

Em virtude dessa nova prática, muitas escolas, já em seu processo seletivo para docentes, recrutam profissionais para atuar exclusivamente com Redação. Isso sugere que essas instituições compreendem o processo de ensino e de aprendizagem da escrita como algo possível e até necessário de dissociar do ensino de língua materna. Talvez isso esteja sendo motivado pela concepção de produção textual como um produto final a ser posto na vitrine.

o problema que essa prática pode gerar é complexo e de difícil resolução, tendo em vista a dinâmica das escolas e da própria profissão docente. Por exemplo, se os professores de Língua Portuguesa e de Redação não tiverem um trabalho sincronizado, em função da falta de tempo para trocarem ideias com seus pares, é possível que uma disciplina não sirva de base para outra.

III) A concepção de língua, de linguagem, de texto e de escrita: é preciso pensar de quais concepções se partirá para propor uma sistematização de ensino nessa área. Isso porque esses conceitos estarão diretamente interligados com a perspectiva e, consequentemente, com a abordagem que será adotada para o ensino de produção de texto escri-

8 Ver: SANTOS, Letícia da Silva. Proficiência em língua materna: um novo olhar para a avaliação de produção textual. Dissertação de mestrado em Linguística Aplicada. PPGL/UFRGS. 2010. Orientador: Prof. Dr. Paulo Coimbra Guedes. 
to. É possível garantir que professores de diferentes disciplinas (Língua Portuguesa e Redação) adotarão perspectivas semelhantes de ensino? Quais as implicações no caso de os profissionais da área assumirem perspectivas teóricas e práticas diferentes na forma de trabalhar com as mesmas turmas?

Por exemplo, se o professor de LP estiver trabalhando a língua materna numa perspectiva de ensino tradicional, ou seja, amparada fundamentalmente nos estudos de ordem gramatical e prescritiva, baseadas em modelos; e o professor de RD adotar uma perspectiva interacionista, isto é, voltada para as práticas reais efetuadas por meio da linguagem; nestes casos, é possível que essas disciplinas não se complementem, ou até aparentem tratar de objetos distintos.

Adisciplinarização da produção textual escritana educação básica brasileira

IV) Objetos, conhecimentos e habilidades: outra definição a ser feita diz respeito ao que deve ser abordado referente a essa prática em cada uma das disciplinas (Língua Portuguesa e Redação). Qual será o objeto de ensino? Quais conhecimentos serão explorados para o desenvolvimento de competências e de habilidades de escrita? Aspectos gramaticais podem ser dissociados das aulas de produção escrita? Aspectos discursivos e textuais podem ser tratados apenas nas aulas de Redação? Qual a linha que separa e diferencia - se é que isso é possível - o ensino de Língua Portuguesa do ensino de Redação? E a leitura desempenha qual papel neste processo?

Para Guedes (2009), por exemplo, a tarefa do aluno nas aulas de redação é escrever para produzir conhecimento/entendimento. 0 papel do professor de redação, por sua vez, é orientar a reescrita do aluno. Para o autor, o aluno deve ser motivado a escrever a partir do tema, isto é, o assunto é o ponto de partida do processo de escrita, é a provocação para escrever. Nesse processo, o foco não está no reconhecimento e no domínio de regras e de estruturas de gêneros textuais específicos. 0 foco das atividades está em levar o aluno a dominar as qualidades discursivas do texto: unidade temática, objetividade, concretude, questionamento. Esse autor propõe que o aluno comece escrevendo sobre a realidade interior e, posteriormente, sobre a realidade social mais próxima. Isso significa que o aluno vai passar da auto-observação e memória à observação da realidade concreta, chegando à abstração. Nessa proposta, há uma sequência de tipologias textuais a ser trabalhada: 1) narrativa, 2) descritiva, 3) dissertativa (maior grau de abstração). O objeto das aulas é 
Fabiana Veloso

de Melo Dametto

Jeferson Luís

Carvalho

Marcia Cristina

Corrêa

186 o discurso, entendido como a colocação em funcionamento de recursos expressivos de uma língua com certa finalidade, atividade que sempre se dá numa instância concreta entre um locutor e um alocutário.

Já para autores como Ferrarezi e Carvalho (2015), a escola deve ensinar o aluno a escrever de forma sistematizada, constante, metódica e progressiva. Nessa perspectiva, escrever é uma competência a ser adquirida por meio do desenvolvimento de habilidades linguístico-discursivas. Para eles, o aluno precisa dominar, primeiramente, as estruturas mínimas da elaboração textual, como a produção de pequenos períodos através de atividades voltadas para esse fim. Além disso, o aluno deve aprender a resumir, a expandir, a ordenar, a juntar informações. A atividade de escrita parte de um "sul" e vai rumo a um "norte". Dessa forma, o aluno tem sempre em mente sob quais circunstâncias e para qual finalidade escreverá. Nessa proposta também há um destaque especial para a função social do texto, isto é, a escrita deve ser sempre útil; escreve-se para uma finalidade específica, com objetivos estabelecidos.

A partir apenas desses dois posicionamentos - aqui superficialmente apresentados em caráter de exemplificação - , percebe-se que a prática de ensino e da aprendizagem da produção textual na escola pode assumir diferentes formatos. Logo, quando a equipe diretiva de uma escola decide implantar uma disciplina denominada Redação, é preciso levar em consideração qual será, de fato, o(s) objeto(s) de ensino a ser(em) tratado(s). Caso contrário, é possível que diferentes professores de Redação assumam objetos de ensino igualmente distintos para suas aulas e, com isso, a escola não obtenha, de fato, bons resultados com as aulas de produção de texto escrito ao longo dos anos, tendo em vista que esse processo será marcado por lacunas, rupturas e até mesmo contradições. Nestes casos, é inviável pensar em uma política de ensino de produção escrita que perpasse toda a educação básica e, com isso, reflita o trabalho sistematizado, progressivo e sincronizado de toda uma instituição ou mesmo de um sistema de ensino (municipal, estadual etc.).

V) Programa, sistematização do ensino da produção escrita: partindo dessas questões iniciais, outras maiores e mais complexas surgem: como sistematizar o ensino de escrita ao longo da formação básica? o que trabalhar em cada ano/série sobre escrita, de modo que não haja sobreposição ou falta de conhecimentos/conteúdos ao longo da formação escolar? O que é pertinente explorar no $6^{\circ}$ ano do EFII? O que é per- 
tinente explorar no $7^{\circ}$ ano do EFII? E assim por diante. Neste caso, basta solicitar produções e mais produções de textos? Serão trabalhadas diferentes modalidades de textos ao longo da Educação Básica? Todas as modalidades de textos comumente abordadas na escola (conto, crônica, carta, romance, poesia, editorial, resenha, resumo etc.) devem ser abordadas nas aulas de Redação? Isto é, referente a quais modalidades de textos os alunos devem dominar práticas de produção escrita?

Durante nossas práticas de sala de aula, muito discutimos sobre o que é ou não relevante para a aprendizagem do aluno. Pensando nisso de uma perspectiva mais pragmática, talvez até utilitarista em alguns momentos, questionamo-nos sobre até que ponto é pertinente ensinar ao aluno, por exemplo, certos gêneros textuais.

Percebemos, também, que uma coisa é explorar diferentes mo-

Adisciplinarização da produção textual escritana educação básica brasileira dalidades de textos escritos com a finalidade de reconhecer suas estruturas, modos de funcionamento e circulação social; Neste caso, o foco estaria na identificação, reconhecimento e compreensão do texto. Outra coisa é, a partir dessa atividade inicial, propor aos alunos a produção dessas mesmas modalidades de textos. Em função disso, optamos por fazer a distinção entre modalidades de textos que seriam explorados apenas com o primeiro propósito daqueles a partir dos quais seriam propostas posteriormente atividades de produção textual. Contudo, esta foi uma decisão que nasceu de nossa prática, sem qualquer fundamentação teórica. Casos como este colocam em evidência a fragilidade da disciplina de Redação no momento atual.

VI) Metodologia e Operacionalização das práticas de ensino: relacionado ao que já foi apresentado, é preciso definir quais práticas serão empregadas em sala de aula para viabilizar o trabalho do professor. Com várias turmas (de 25 a 30 alunos) e aulas semanais, é possível dar retorno a todos os alunos? É possível solicitar uma produção por semana? Como resolver casos pontuais de dificuldades em escrita?

De acordo com relatos feitos por Guedes (2009) e tomando como referência nossa própria atividade como professores de Redação, podemos afirmar que o ensino de massa não é compatível com aulas que tenham como foco conduzir o aluno, de forma gradual e progressiva, ao domínio das diferentes habilidades necessária para a produção dos mais variados textos.

Esse é um trabalho árduo, que demanda tempo, paciência, olhar 
Fabiana Veloso de Melo Dametto

Jeferson Luís Carvalho

Marcia Cristina Corrêa atento para as individualidades. Caso contrário, a prática de produção de textos escritos apenas fortalece as desigualdades entre os alunos e gera entre eles competitividade e angústias advindas da certeza de que a maioria deles não sabe escrever, que não domina a língua materna e que escrever bem é questão de dom.

Defendemos, portanto, que a viabilidade da disciplina é uma questão crucial. Operacionalizar o ensino da produção escrita não é tarefa fácil. Não quando se pretende fazer, de fato, um trabalho que considere as individualidades. Além disso, é comum que o professor de Redação seja aquele que tem horas vagas (precisa fechar a carga horária mínima), ou seja, o mesmo aluno pode ter vários professores de Redação ao longo de sua vida escolar ou, até mesmo, no mesmo ano letivo. Isso dificulta ainda mais esse processo. A relação entre aluno e professor de Redação é muito estreita, uma vez que o aluno passa a compartilhar suas ideias, sentimentos, valores com esse leitor/avaliador de seus textos. A confiança que resulta de um acompanhamento prolongado é outro fator fundamental que interfere nos resultados desse processo.

VII) Como avaliar a proficiência em produção textual escrita?: por fim, não poderiam ficar de fora questões relativas à avaliação. Quando se trata de uma disciplina, é preciso pensar na possibilidade de reprovação dos alunos. Mas como avaliar o rendimento/ proficiência em produção escrita ao longo dos anos, tendo em vista que esse é um conhecimento que acreditamos ser dinâmico e que se adquire de forma progressiva, em processo? o que exigir em termos de rendimento em escrita em cada nível/ano? Como mensurar/ traduzir isso em números/conceitos? A disciplina de Redação conta com critérios de avaliação bem definidos que possibilitem atestar a aprovação ou a reprovação de um aluno? Quais os mecanismos que legitimam a disciplina?

Mais uma vez, recorremos à nossa experiência para refletir sobre essas questões. Sempre sentimos muita dificuldade para avaliar textos escritos. Nesse processo, há uma boa parcela de subjetividade no modo de olhar os textos. Para minimizar esse fator, sabe-se que, por exemplo, nos vestibulares e concursos, as comissões de avaliadores de redação trabalham em pares. Cada texto é avaliado, pelo menos, por dois profissionais. Mas e quando isso é feito na escola? 
Presenciamos, inúmeras vezes, a dificuldade que é conseguir comprovar a deficiência de um aluno em produção textual escrita. O aluno não aceita uma reprovação. Os pais não aceitam. A equipe diretiva não aceita. É difícil conseguir comprovar para um leigo no assunto o quanto um texto é problemático, o quanto um aluno tem dificuldades com a escrita. Ainda mais quando ele consegue aprovação nas demais disciplinas. Foram diversos os casos de alunos que avançaram de ano por diversas vezes apresentando sérias limitações com a produção de textos, mas que alcançavam boas médias em outras áreas, inclusive em Língua Portuguesa e em Literatura. Sem contar os inúmeros casos de alunos que, ao final do Ensino Médio, já haviam sido aprovados em exames seletivos para ingresso no Ensino Superior. Casos como esses deflagram a incoerência, muitas vezes, entre essas disciplinas e as demais.

Há pais que, inclusive, na tentativa de advogar em defesa de seus filhos, usam argumentos relacionados à falta de "dom" dos alunos para escrever. Outra justificativa comum é a predileção por determinada área do conhecimento. Alunos com propensão às exatas estariam dispensados, na visão dos pais, do compromisso de escrever bem.

Em virtude dessas situações que vivenciamos no dia a dia das escolas, acreditamos que o fator avaliativo da disciplina é de fundamental importância. É difícil quantificar processo, o mais fácil é mensurar o produto final. Contudo, esse procedimento requer ferramentas muito claras e precisas que, na maioria das vezes, nos conduzem a uma avaliação injusta, mecânica e inconsistente, que mais desmotiva os alunos do que, de fato, os ajuda a ter a noção exata de sua caminhada em escrita.

Em busca de respostas a essas questões, foi realizada uma breve pesquisa exploratória sobre o tema. Contudo, não foram encontrados materiais publicados no Brasil que tratem sobre a disciplina de Redação. Apenas há títulos que abordam o ensino da escrita, em especial no EFII. Outro ponto a destacar diz respeito ao caráter prático dessas atividades. Todas as consultadas cabem à realização de oficinas de produção textual, nas quais não há a exigência ou a necessidade de se avaliar o rendimento do aluno em escrita por meio de atribuição de nota/conceito, como deve acontecer em uma disciplina. 


\section{Considerações finais}

Não há dúvidas da importância da produção textual escrita na história acadêmica do estudante brasileiro. Com o retorno da redação ao ves-

Fabiana Veloso de Melo Dametto

Jeferson Luís Carvalho

Marcia Cristina Corrêa tibular em 1977, passou-se a encarar a escrita como um meio para um fim. Surgiu, com isso, a necessidade de criação de um tempo e espaço - uma disciplina - destinados especificamente ao ensino de redação. Essa demanda, que vai de encontro ao que apregoam os pesquisadores da área, cada vez mais ganha espaço nas instituições de ensino privadas, em especial naquelas em que se acredita que o sucesso escolar está diretamente ligado ao acesso a um curso superior - processo que utiliza a produção textual como uma barreira classificatória a ser transposta.

Uma das questões mais discutidas por profissionais da área de Letras é como e o que trabalhar em sala de aula na disciplina de Redação. Encontrar as respostas a essas perguntas é um desafio diante da realidade que se apresenta: normalmente, as instituições de ensino reservam um período semanal para a disciplina em turmas com aproximadamente 30 alunos. Além disso, em determinados momentos da caminhada escolar, a Redação é vista de modo inferior se comparada a outras disciplinas mais "nobres" do currículo. Tendência esta que tende a ser erradicada - por motivos óbvios - no Ensino Médio e, em especial, no terceiro ano. Na maioria das situações, trabalhando de forma independente à disciplina de Língua Portuguesa, o professor de Redação defronta-se com a necessidade de ter de ler, avaliar, realizar feedback e, ainda, ensinar em cinquenta minutos por semana com cada turma.

É nesse contexto que se espera que o professor faça com que os alunos adquiram a capacidade de elaborar um texto dissertativo-argumentativo para ser aprovado por uma banca avaliadora. Esse caráter de ensino para uma avaliação e suas consequências já foram largamente enfatizados e discutidos pela literatura da área ${ }^{9}$, em especial no fim dos anos de 1970. Atualmente, afirma-se que:

[...] frequentemente ouvimos, especialmente em escolas para alunos de renda mais alta, mais, ultimamente, com a implantação do ProUni, em uma gama ainda maior de centros de ensino,

9 Ver, por exemplo, LEMOS, Cláudia. Redações de vestibular: algumas estratégias. In: Cadernos de Pesquisa da Fundação Carlos Chagas. N. 23. 1977; NETTO, A. Ribeiro. O vestibular no sistema educacional brasileiro. In: Cadernos de Pesquisa da Fundação Carlos Chagas. N. 24.1978 e SOARES, Magda. A redação no vestibular. In: Cadernos de Pesquisa da Fundação Carlos Chagas. N. 24, 1978. 
que o sucesso do aprendizado em língua portuguesa será medido no momento do vestibular (ou, no caso igualmente vigente na atualidade, pelo Enem). Isto é, há um discurso, diluído e perpetuado entre escola, professores, pais e alunos, de que o sucesso na aprendizagem em língua portuguesa será aferido, de fato, ao menos oficialmente, no momento em que esse conhecimento for posto à prova em alguma avaliação promovida por uma instituição de ensino superior (NUNES, 2014, p. 55).

Inseridos neste debate e partindo de uma abordagem sociointeracionista e ergonômica, o presente artigo buscou apresentar e mapear, ainda de maneira preliminar, essa realidade que, apesar de estar cada vez mais viva e presente na rotina escolar, tem sido pouco abordada

Adisciplinarização da produção textual escritana educação básica brasileira - principalmente dentro do escopo de atuação do Ensino Médio. Em virtude disso, acreditamos que é essencial o debruçar-se sobre as especificidades e, consequentemente, sobre as dificuldades que emergem desse processo de ensino da produção textual escrita em diversas escolas brasileiras.

Cumpre destacar que responder aos questionamentos aqui suscitados é o desafio de nossas pesquisas daqui para frente. Isso porque, ao respondermos a tais questionamentos, acreditamos que poderemos nos aproximar de um caminho mais seguro a ser seguido dentro de um campo, hoje, movediço e, por isso, repleto de incertezas. Diante do caráter informal aplicado à disciplina de Redação, visto que há uma ausência significativa de consenso sobre os objetos de ensino dessa disciplina, sobre a metodologia a ser assumida, bem como sobre o objetivo a ser alcançado, mapear uma realidade concreta demandará uma pesquisa extensa e, ainda assim, sem garantia de um quadro preciso. 


\section{REFERÊNCIAS}

BITTENCOURT, C. M. F. Disciplinas escolares: história e pesquisa. In:

Fabiana Veloso

de Melo Dametto

Jeferson Luís

Carvalho

Marcia Cristina

Corrêa OLIVEIRA, M. A. T. de; RANZI, S. M. F. (Orgs.). História das disciplinas escolares no Brasil: contribuição para o debate. Bragança paulista: EDUSF, 2003. p. 9-38.

BRASIL. MINISTÉRIO DA EDUCAÇÃO. Parâmetros Curriculares Nacionais: linguagens, códigos e suas tecnologias - arte. Brasília: Secretaria de Educação Média e Tecnológica. Disponível em: www. portal.mec.gov.br. Acesso em: 08 set. 2015.

BRONCKART. Jean-Paul. Atividade de linguagem, textos e discurso: por um interacionismo sócio-discursivo. São Paulo: Educ, 1999/2007. Ensinar: um "métier" que, enfim, sai da sombra. In: MACHADO, A. R. e colaboradores. Linguagem e Educação - 0 trabalho do professor em uma nova perspectiva. Campinas: Mercado de Letras, 2009.

CHERVEL, André. História das disciplinas escolares: reflexões sobre um campo de pesquisa. Teoria e Educação. n. 2, 1990, p. 177-229.

ENDRUWEIT, M. L; OTHERO, G. A. de. O vestibular, a redação e a sala de aula: um percurso histórico. In: REBELLO, L. S.; FLORES, V. N. do (Orgs.). 0 texto de vestibular em perspectiva. Porto Alegre: Editora da UFRGS, 2014. p. 13 -36.

FERRAREZI JR., Celso; CARVAlHo, Robson Santos de. Produzir textos na educação básica: o que saber, como fazer. São Paulo: Parábola, 2015.

GOLDNADEL, Marcos. Implicações do reconhecimento das condições de produção da dissertação escolar para o trabalho com redação na aula de Língua Portuguesa. In: REBELLO, L. S.; FLORES, V. N. do (Orgs.). 0 texto de vestibular em perspectiva. Porto Alegre: Editora da UFRGS, 2014. p. 63-89. 
GOMES, Neiva M. Tebaldi. Redação de vestibular: que gênero é esse? In: REBELLO, L. S.; FLORES, V. N. do (Orgs.). o texto de vestibular em perspectiva. Porto Alegre: Editora da UFRGS, 2014. p. 13 -36.

GUEDES, Paulo Coimbra. Da redação à produção textual: o ensino da escrita. São Paulo: Parábola Editorial, 2009.

A disciplinarização da produ-

MACHADO, Anna Raquel (Org.). o ensino como trabalho: uma ção textual abordagem discursiva. Londrina: Eduel, 2004. escritana educação básica

NUNES, Paula Ávila. Proficiência ou rendimento? O que a redação brasileira de vestibular avalia? In: REBELLO, L. S.; FLORES, V. N. do (Orgs.). O texto de vestibular em perspectiva. Porto Alegre: Editora da UFRGS, 2014. p. 53-63.

Recebido em 06 de março de 2017. Aceito em 05 de maio de 2017. 
